Volume 10, Nomer 01, 2020

\title{
Tingkat Resiliensi dengan Ide Bunuh Diri Pada Remaja
}

\author{
Kania Febrya Putri ${ }^{1}$, Duma Lumban Tobing ${ }^{2}$ \\ ${ }^{1,2}$ Fakultas Ilmu Kesehatan Universitas Pembangunan Nasional "Veteran" Jakarta \\ Jl, Limo Raya kelurahan limo, Kecamatan Limo Kota Depok, Kode Pos 16515 \\ Email: kaniafebryaputri@gmail.com¹, duma.tobing@upnvj.ac.id ${ }^{2}$
}

\begin{abstract}
Abstrak
Pendahuluan: World Health Organization (WHO) menetapkan bunuh diri sebagai fenomena global di seluruh wilayah di dunia penyebab kematian terbanyak kedua di tahun 2016 dengan rentang usia 15-26 tahun. Banyaknya perubahan yang terjadi pada masa remaja, seperti fisik, hormonal, sosial, dan psikososial, sering kali memicu ketidakstabilan emosi pada remaja yang berujung pada timbulnya ide bunuh diri. Oleh karena itu, dibutuhkan suatu kemampuan agar remaja dapat beradaptasi dengan baik, salah satunya dengan meningkatkan resiliensi Tujuan: Tujuan penelitian, yaitu untuk mengetahui hubungan tingkat resiliensi dengan ide bunuh diri pada remaja.

Desain: Penelitian ini melibatkan 231 responden berusia 15 sampai 17 tahun yang akan diminta untuk mengisi data demografi, Connor Davidson Resilience Scale (CD-RISC), dan Suicidal Ideation Questionnaire (SIQ).

Hasil: Hasil penelitian menemukan adanya hubungan antara tingkat resiliensi dengan ide bunuh diri. Terdapat temuan menarik, ide bunuh diri juga ditemukan pada remaja dengan orang tua tidak bercerai dan tingkat resiliensi sedang.

Kesimpulan: Meningkatkan resiliensi dapat menjadi salah satu upaya penting untuk mencegah dan mengurangi ide bunuh diri pada remaja.
\end{abstract}

Kata Kunci: Ide Bunuh Diri, Remaja, Resilensi

\section{Pendahuluan}

Masa remaja sering kali disebut sebagai masa peralihan dari masa anak-anak menuju dewasa. ${ }^{1}$ Banyak sekali perubahan yang terjadi, baik secara fisik, psikologis, hormonal, dan sosial pada masa remaja. ${ }^{2}$ Adanya tekanan sosial yang menuntut remaja untuk

\begin{abstract}
Introduction: World Health Organization (WHO) had claimed suicide as the second-leading cause of death among 15- to 26-year-olds in 2016. Emotion dysregulation might impact suicidal ideation among adolescents. To prevent suicidal thoughts and suicide, the literature suggested to increase resilience ability. This ability would help adolescent adapted to the environmental changes properly.

Objective: . The aims of this research was to analyze the correlation of resilience, age, gender, marital status of parents, and suicidal ideation among adolescents.

Design: .Two hundred and thirty one participants age ranged 15-17 were recruited for this research. Data on demographic was collected and participants would be asked to solve Connor Davidson Resilience Scale (CD-RISC) and Suicidal Ideation Questionnaire (SIQ).

Result: This research revealed the correlation found between resilience and suicidal ideation. Suicidal ideation also can be found in adolescents with non-divorced parents and moderate resilience.

Conclusion: Fostering and increasing resilience ability might be important effort to prevent and reduce suicidal ideation among adolescents.
\end{abstract}

Keywords: Suicide Idea, Teenager, Resilience

menampilkan pola kehidupan sosial baru seperti merubah tingkah laku anak-anak ke dewasa membuat remaja merasa tidak nyaman dan berakibat pada ketidakstabilan emosi yang berakhir pada timbulnya ide bunuh diri. ${ }^{3}$ Bunuh diri merupakan respons maladaptif 
dalam rentang respons protektif diri. ${ }^{6}$ Bunuh diri didefinisikan sebagai suatu tindakan yang dilakukan individu untuk membunuh diri sendiri. ${ }^{7}$ World Health Organization (WHO) menyampaikan, bunuh diri telah menjadi fenomena global sebagai penyebab kematian kedua terbanyak pada tahun 2016 dengan temuan terbanyak terjadi pada rentang usia 15 sampai 29 tahun. Diperkirakan ada lebih dari 800.000 orang meninggal setiap tahun akibat bunuh diri dan lebih dari $79 \%$ kasus bunuh diri terjadi di negara berpenghasilan rendah sampai menengah. ${ }^{8}$ Data statistik WHO (2018) sejak tahun 2000 hingga 2016 memaparkan angka kematian akibat bunuh diri di Indonesia mencapai $3,4 \%$ dari 100.000 populasi. Angka ini meningkat sebesar $0,5 \%$ dari hasil temuan sebelumnya, yaitu $2,9 \%$ dari 100.000 populasi. ${ }^{9}$

Tidak sedikit portal berita menampilkan berita bunuh diri di Indonesia. Salah seorang siswi asal SMKN 1 Kedawung Sragen ditemukan tewas gantung diri pada 23 Oktober 2018. Diketahui bahwa sudah satu minggu siswi tersebut tidak sekolah, diduga akibat masalah keluarga. ${ }^{10}$ Baru-baru ini remaja Dompu, Nusa Tenggara Barat (NTB), diberitakan mengalami darurat bunuh diri. Tercatat 7 kasus bunuh diri dalam kurun waktu 3 bulan di Kecamatan Hu'u, Kabupaten Dompu, NTB. Kasus terbaru, yakni seorang murid 17 tahun harus meregang nyawa akibat meminum insektisida pada 17 Maret 2019. ${ }^{11}$ Dapat disimpulkan bahwa, bunuh diri di Indonesia bukan hanya terjadi pada usia dewasa. Namun, bunuh diri juga dapat terjadi pada usia remaja.

Kejadian bunuh diri tidak memiliki penyebab tunggal. Pada individu yang bunuh diri sering kali ditemukan rendahnya sistem dukungan sosial seperti kekerabatan dan teman atau keimanan, pekerjaan, dan kelompok dukungan masyarakat. ${ }^{12}$ Adanya perceraian orang tua memberikan dampak tersendiri bagi remaja, seperti malu, mudah marah, sulit berkonsentrasi, kehilangan rasa hormat terhadap orang tua, menyalahkan orang tua, melakukan sesuatu yang salah, tidak mempunyai tujuan hidup, merasa tidak aman dengan lingkungan sekitar, dan lain-lain. ${ }^{13}$ Adanya konflik dengan orang tua atau kakak dapat memicu distres selama bertahun-tahun dan memunculkan emosi negatif seperti stres, marah, dan perasaan malu. ${ }^{14}$ Individu dengan distres psikologis mempunyai risiko kematian lebih tinggi dibandingkan dengan individu tanpa distres psikologis. ${ }^{15}$ Resiliensi telah diketahui bahwa dapat menurunkan tingkat distres psikologis seseorang, dengan begitu angka kematian akibat bunuh diri pun dapat ditekan. ${ }^{16,17}$

Resiliensi dapat diartikan sebagai memiliki respons sehat terhadap lingkungan yang menimbulkan stres. ${ }^{7}$ Adapun definisi resiliensi remaja, yaitu prediksi kemampuan remaja untuk bertahan dalam kondisi yang kurang menguntungkan atau penuh tekanan. ${ }^{18}$ Remaja yang resilien memiliki kehidupan lebih baik karena resilien memunculkan kemampuan impulse control, optimism, empathy, dan self-efficacy. Kemampuan resilien ini membuat remaja dapat mengartikan peristiwa sulit dengan positif sehingga remaja mampu mengubah peristiwa sulit menjadi keuntungan yang dapat mendorongnya untuk mengembangkan kemampuan dan kemandirian. ${ }^{19}$

Melalui penelitian ini, perawat dapat mengetahui gambaran seperti apa tingkat resiliensi dan ide bunuh diri pada remaja. Di mana resiliensi pada kelompok yang peneliti ingin uji ini dipandang sebagai investasi dalam diri individu yang diharapkan dapat muncul saat individu tersebut mengalami kesulitan. Perawat juga diharapkan dapat melakukan penilaian terhadap faktor risiko maupun faktor protektif, membuat strategi bagaimana caranya meningkatkan resiliensi pada remaja, dan menjalankan perannya sebagai advokat guna memobilisasi masyarakat untuk mengurangi dan mencegah faktor-faktor yang berkontribusi

terhadap perilaku bunuh diri pada remaja. 
Tabel 2. Frekuensi Proporsi Jenis Kelamin, Status Perkawinan Orang Tua, Tingkat Resiliensi, dan Ide Bunuh Diri Remaja SMA "X" Purwakarta, $2019(n=231)$ bertujuan untuk mengetahui atau mengidentifikasi tingkat resiliensi dengan ide bunuh diri pada remaja di SMA "X" Purwakarta. Sampel diambil secara acak menggunakan stratified random sampling dan berdasarkan perhitungan rumus Slovin, 231 remaja akan dilibatkan dalam penelitian. Adapun kriteria responden lain yang akan diteliti, yaitu remaja berusia 14-17 tahun, hadir saat penyebaran kuesioner, dan bersedia mengisi kuesioner data demografi, 25 pernyataan Connor-Davidson Resilience Scale (CD-RISC), dan 30 pernyataan Suicidal Ideation Questionnaire (SIQ) Data yang sudah terkumpul akan dianalisis menggunakan Uji Chi Square.

\section{Hasil}

Dari hasil penelitian dan uji statistik yang dilakukan maka hasil terkait usia remaja pada tempat penelitian yang dilakukan, jenis kelamin, status perkawinan, tingkat resiliensi dan ide bunuh diri yang merupakan data-data univariat yang tercantum pada tabel 1 dan tabel 2 dibawah ini

Tabel 1. Distribusi Usia Remaja SMA " $X$ " Purwakarta, $2019(n=231)$

\begin{tabular}{cccccccc}
\hline $\begin{array}{c}\text { Varia- } \\
\text { bel }\end{array}$ & Mean & $\begin{array}{c}\text { Me- } \\
\text { dian }\end{array}$ & Mode & SD & $\begin{array}{c}\text { Min- } \\
\text { Max }\end{array}$ & 95\% CI \\
\hline Usia & 16.18 & 16.00 & 16 & 0.711 & $\begin{array}{c}15- \\
17\end{array}$ & $\begin{array}{c}16.09- \\
16.27\end{array}$ \\
\hline
\end{tabular}

Tabel 1 memperlihatkan bahwa dari 231 responden remaja rata-rata usianya adalah 16.18 tahun. Usia tengah dan usia paling banyak pada remaja, yaitu 16 tahun dengan usia minimum dan maksimum secara berturut-turut 15 dan 17 tahun. Nilai variasi 0.711 dengan nilai kepercayaan $(\mathrm{CI}=95 \%)$, rata-rata usia responden antara 16.09 tahun sampai 16.27 tahun.

\begin{tabular}{lcc}
\hline \multicolumn{1}{c}{ Variabel } & Frekuensi & Presentase \\
\hline Jenis Kelamin & & \\
1. Laki-Laki & 67 & $29 \%$ \\
\hline 2. Perempuan & 164 & $71 \%$ \\
\hline Status Perkawinan & & \\
orang tua & & \\
1. Tidak Bercerai & 213 & $92.2 \%$ \\
2. Bercerai & 18 & $7.8 \%$ \\
\hline Tingkat Resiliensi & & \\
1. Tinggi & 51 & $22.1 \%$ \\
2. Sedang & 122 & $52.8 \%$ \\
3. Rendah & 58 & $25.1 \%$ \\
\hline Ide Bunuh Diri & & \\
1. Tidak Berisiko & 219 & $94.8 \%$ \\
2. Berisiko & 12 & $5.2 \%$ \\
\hline
\end{tabular}

Tabel 2 menunjukkan jumlah responden laki-laki sebanyak 67 orang $(29 \%)$ dan perempuan 164 orang $(71 \%)$. Dari 231 responden terdapat 18 remaja $(7.8 \%)$ dengan orang tua bercerai, sedangkan 213 remaja lainnya $(92.2 \%)$ dengan orang tua tidak bercerai.Tingkat resiliensi dibagi ke dalam tiga tingkatan yaitu, tingkat resiliensi rendah dalam rentang kuartil satu (Q1), kuartil dua (Q2) dan kuartil tiga (Q3) sebagai kelompok tingkat resiliensi sedang, dan kuartil empat (Q4) menggambarkan tingkat resiliensi tinggi. ${ }^{20,21}$ Berdasarkan pedomen tersebut diperoleh Q1 (40-68), Q2 (69-78), Q3 (79-84), dan Q4 (85-95).

Dari 231 remaja yang berpartisipasi dalam penelitian terdapat 51 orang $(22.1 \%)$ dengan tingkat resiliensi tinggi, 122 orang (52.8\%) mempunyai resiliensi sedang, dan 58 orang $(25.1 \%)$ tingkat resiliensinya rendah.

Total skor lebih dari 40 termasuk ke dalam kategori berisiko, sedangkan total skor 40 atau kurang dari itu masuk ke dalam kategori 
tidak berisiko. ${ }^{22-24}$ Terdapat 219 remaja (94.8\%) yang masuk ke dalam kategori tidak berisiko dan 12 remaja (5.2\%) masuk ke dalam kategori berisiko atau dapat dikatakan sebagai memiliki ide bunuh diri yang signifikan.

Tabel 3. Hubungan Tingkat Resiliensi dengan Ide Bunuh Diri pada Remaja SMA "X" Purwakarta, $2019(\mathrm{n}=231)$

\begin{tabular}{|c|c|c|c|c|c|c|c|}
\hline \multirow{3}{*}{$\begin{array}{l}\text { Tingkat } \\
\text { Resiliensi }\end{array}$} & \multicolumn{4}{|c|}{ Ide Bunuh Diri } & \multirow{2}{*}{\multicolumn{2}{|c|}{ Total }} & \multirow{3}{*}{ Nilai $\mathbf{P}$} \\
\hline & \multicolumn{2}{|c|}{$\begin{array}{c}\text { Tidak } \\
\text { Berisiko } \\
\end{array}$} & \multicolumn{2}{|c|}{ Berisiko } & & & \\
\hline & $\mathrm{n}$ & $\%$ & $\mathrm{n}$ & $\%$ & $\mathrm{n}$ & $\%$ & \\
\hline Tinggi & 51 & 100 & 0 & 0 & 51 & 100 & \\
\hline Sedang & 121 & 99.2 & 1 & 0.8 & 122 & 100 & 0.000 \\
\hline Rendah & 47 & 81.0 & 11 & 19.0 & 58 & 100 & \\
\hline
\end{tabular}

Berdasarkan tabel tersebut diketahui bahwa tidak ada responden dengan tingkat resiliensi tinggi yang mempunyai ide bunuh diri berisiko. Semua responden yang mempunyai resiliensi tinggi, 51 orang (100\%), berada pada kategori ide bunuh diri tidak berisiko. Dari 122 remaja yang mempunyai resiliensi sedang atau cukup, terdapat 121 orang (99.2\%) yang termasuk ke dalam ide bunuh diri tidak berisiko dan 1 orang $(0.8 \%)$ ide bunuh diri berisiko.

Sedangkan 58 orang lainnya, yaitu 47 orang $(81.0 \%)$ ide bunuh diri tidak berisiko dan 11 orang (19.0\%) ide bunuh diri berisiko mempunyai resiliensi yang rendah. Setelah melakukan uji statistik Chi Square dengan bantuan aplikasi SPSS, didapatkan nilai P sebesar $0.000(\mathrm{p}<0.05)$. Artinya, terdapat hubungan antara tingkat resiliensi dengan ide bunuh diri. Oleh karena tabulasi berbentuk $3 \times 2$, nilai OR tidak dapat diketahui. Meskipun begitu, tetap dapat ditarik kesimpulan bahwa $\mathrm{HO}$ dalam penelitian ini ditolak dan Ha diterima.

\section{Pembahasan}

Resiliensi dan ide bunuh diri memiliki hubungan yang signifikan pada remaja. ${ }^{25} \mathrm{Ke}-$ mampuan resiliensi yang dapat menurunkan tingkat distres psikologis menyebabkan penurunan terhadap angka kejadian bunuh diri. Individu dengan distres psikologis mempunyai risiko kematian lebih tinggi dibandingkan dengan individu yang tidak memiliki distres psikologis. ${ }^{15}$ Dengan meningkatkan resiliensi, maka tingkat distres psikologis akan turun karena keduanya memiliki hubungan negatif. ${ }^{16,26}$

Ide bunuh diri sedang hingga berat ditemukan lebih tinggi pada pasien depresi dengan tingkat resiliensi rendah dibandingkan pada pasien depresi dengan tingkat resiliensi tinggi. ${ }^{27}$ Berdasarkan hasil tersebut, dapat ditarik kesimpulan bahwa resiliensi memoderasi risiko depresi dan gejala kecemasan terhadap ide bunuh diri pada pasien dengan depresi atau gangguan kecemasan yang dapat meningkatkan risiko bunuh diri.

National Youth Risk Behavior Survey 2013 yang dilakukan pada remaja sekolah menengah di seluruh Amerika Serikat menunjukkan $17 \%$ remaja secara serius mempertimbangkan bunuh diri dalam 12 bulan terakhir, $13.6 \%$ merencanakan upaya bunuh diri, dan $8 \%$ melakukan upaya bunuh diri. ${ }^{28}$ Timbulnya ide bunuh diri pada remaja dapat disebabkan oleh tuntutan terhadap remaja yang bersekolah di sekolah dengan reputasi akademik ternama atau stres akademik. Bagi remaja yang mengalami kesulitan dalam sosial emosional akan mengalami kesulitan dalam memenuhi tuntutantuntutan tersebut. ${ }^{29}$

Terdapat hubungan negatif antara stres akademik dengan kesehatan mental. ${ }^{30}$ Artinya, semakin tinggi stres akademik yang dialami oleh remaja maka kesehatan mental remaja tersebut semakin rendah. Begitupun sebaliknya. Hal tersebut dapat terjadi apabila remaja tidak dapat mengatasi tuntutan atau masalah yang

terjadi. Selanjutnya, stres pun muncul dengan karakteristik seperti mudah marah, cepat tersinggung, sulit untuk berkonsentrasi, sukar mengambil keputusan, pemurung, sering 
merasa cemas atau takut, dan tidak berenergi. Selanjutnya, jika remaja tersebut tidak dapat mengatasi stres yang dialaminya, maka remaja tersebut dapat jatuh pada keadaan depresi. ${ }^{31}$

Dari 612 remaja terdapat $45.7 \%$ mengalami depresi sedang, 25.4\% depresi ringan, 19.6\% depresi parah, dan $9.3 \%$ memiliki minimal depresi sesuai Beck Depression Inventory (BDI). ${ }^{32}$ Dalam temuannya juga diketahui bahwa remaja dengan stres akademik berisiko 2.4 kali lebih tinggi mengalami depresi dibandingkan remaja yang tidak mengalami stres akademik. Depresi dan keputusasaan memberi risiko terhadap munculnya ide bunuh diri. $^{33}$

Pada gejala depresi, resiliensi memoderasi hubungan antara stres dan gejala depresi. ${ }^{35}$ Menghadapi remaja dengan perilaku menyimpang, tindakan atau intervensi berupa konseling, terapikognitif dan emotive menjadi salah satu sarana pemecahan masalah dan komunikasi intensif Remaja dengan tingkat ketahanan tinggi dapat menahan efek stres pada gejala depresi. Dengan demikian, remaja yang memiliki tingkat resiliensi tinggi dapat mengumpulkan sumber daya ketahanan untuk mengatasi efek dari stres. ${ }^{34}$ Optimalisasi sarana bimbingan konseling di sekolah atau perawat kesehatan sekolah sebagai faktor protektif diharapkan dapat membantu remaja untuk mengatasi stres, mencegah depresi, dan timbulnya ide bunuh diri. ${ }^{25,32}$

\section{Kesimpulan}

Berdasarkan hasil analisis yang telah dilakukan terkait hubungan tingkat resiliensi dengan ide bunuh diri remaja di salah satu SMA Purwakarta, didapatkan kesimpulan bahwa terdapat hubungan antara tingkat resiliensi dengan ide bunuh diri. Terdapat temuan menarik dalam penelitian ini, di antaranya ide bunuh berisiko tidak hanya ditemukan pada remaja dengan tingkat resiliensi rendah saja, tetapi ide bunuh diri berisiko juga ditemukan pada remaja dengan tingkat resiliensi sedang. Melalui peningkatan faktor protektif dan penurunan faktor risiko, dapat meningkatkan resiliensi pada remaja. Sehingga remaja menjadi mudah beradaptasi terhadap segala perubahan yang terjadi dan diharapkan dapat menurunkan timbulnya ide bunuh diri.

\section{Daftar Pustaka}

1. Aziz S. Pendidikan Seks Perspektif Terapi Sufistik Bagi LGBT. Semarang: Penerbit Ernest; 2017. 207 p.

2. Denich AU, Ifdil I. Konsep Body Image Remaja Putri. J Konseling dan Pendidik. 2015;3(2).

3. Law KC, Khazem LR, Anestis MD. ScienceDirect The role of emotion dysregulation in suicide as considered through the ideation to action framework. Curr Opin Psychol. 2015;3:30-5.

4. Thalib SB. Psikologi Pendidikan Berbasis Analisis Empiris Aplikatif. 1st ed. Jakarta: Prenada Media Group; 2010. 318 p.

5. Tristanti I. Remaja dan Perilaku Merokok. 3rd Univ Res Colloq. 2016;328-42.

6. Stuart GW. Prinsip dan Praktik Keperawatan Kesehatan Jiwa Stuart. 1st ed. Keliat BA, Pasaribu J, editors. Singapore: Elsevier; 2016.

7. Videbeck SL. Buku Ajar Keperawatan Jiwa. Karyuni PE, editor. Jakarta: EGC; 2015.

8. WHO. World Health Statistics 2018 Monitoring Health for the SDGs Sustainable Development Goals. World Heal Organ. 2018;

9. WHO. World Health Statistics 2017 Monitoring Health For The SDGs Sustainable Development Goals. World Heal Organ. 2017;

10. Wardoyo P. Tragis, Siswa SMKN 1 Kedawung Sragen Ditemukan Gantung Diri di Dapur. Seminggu Sempat Tak Masuk Sekolah. Joglosemar News. 2018 [cited 2019 Mar 21]. Available from: https://joglosemarnews.com/2018/10/tragissiswa-smkn-1-kedawung-sragen-ditemukangantung-diri-di-dapur-seminggu-sempat-takmasuk-sekolah/

11. Info Dompu. 7 Kasus Dalam 3 Bulan, Dompu NTB Darurat Bunuh Diri Remaja [Internet]. Kumparan. 2019 [cited 2019 Mar 21]. Available from: https://m.kumparan.com/infodompu/7kasus-dalam-3-bulan-dompu-ntb-daruratbunuh-diri-remaja-1553121419388068264

12. Videbeck SL. Psychiatric-Mental Health Nursing. 5th ed. Lippincott Williams \& 
Wilkins; 2011.

13. Untari I, Putri KPD, Hafiduddin M. Dampak Perceraian Orang Tua Terhadap Kesehatan Psikologis Remaja. PROFESI (Profesional Islam Media Publ Penelit. 2018;15(2).

14. Mukarromah L, Nuqul FL. Dinamika Psikologis pada Pelaku Percobaan Bunuh Diri. J Psikoislamika. 2014;11(2):31-6.

15. Forman-Hoffman V, Muhuri P, Novak S, Pemberton M, Ault K, Mannix D. Psychological Distress and Mortality among Adults in the U.S. General Population. CBHSQ Data Rev. 2014;

16. Mahmood K, Ghaffar A. The Relationship between Resilience, Psychological Distress and Subjective Well- Being among Dengue Fever Survivors. Glob J Human-Social Sci. 2014;

17. Pidgeon AM, Rowe NF, Stapleton P, Magyar $\mathrm{HB}$, Lo BCY. Examining Characteristics of Resilience among University Students: An International Study. Open J Soc Sci. 2014;02(11):14-22.

18. Wardhani RH, Sunarti E, Muflikhati I. Ancaman, Faktor Protektif, Aktivitas, dan Resiliensi Remaja: Analisis Berdasarkan Tipologi Sosiodemografi. J Ilmu dan Konsum. 2017;10(1):47-58.

19. Dewanti A, Suprapti V. Resiliensi Remaja Putri terhadap Problematika Pasca Orang Tua Bercerai. J Psikol Pendidik dan Perkemb. 2014;3(3):164-71.

20. Connor KM, Davidson JRT. Development of a new resilience scale: the Connor-Davidson Resilience Scale (CD-RISC). Depress Anxiety. 2003;18(2):76-82.

21. Davidson JRT. Connor-Davidson Resilience Scale (CD-RISC) Manual. 2018.

22. Reynolds WM, Johnston HF. Handbook of Depression in Children and Adolescents. New York: Plenum Press; 1994.

23. Reynolds WM. Suicidal Ideation Questionnaire: Professional manual. Psychol Assess Resour. 1988;

24. Boege I, Corpus N, Schepker R, Fegert JM. Pilot study: feasibility of using the Suicidal Ideation Questionnaire (SIQ) during acute suicidal crisis. Child Adolesc Psychiatry Ment Health. 2014;8(28):4-9.
25. Kamble R. Resilience, Suicidal Ideation , Depression and Adolescents. Int $\mathrm{J}$ Educ Psychol Res. 2015;4(3):27-30.

26. Azzahra F. Pengaruh Resiliensi Terhadap Distres Psikologis pada Mahasiswa. J Ilm Psikol Terap. 2017;05:80-96.

27. Min J, Lee C, Chae J. Resilience Moderates the Risk of Depression and Anxiety Symptoms on Suicidal Ideation in Patients with Depression and/or Anxiety Disorders. Compr Psychiatry. 2015;56:103-11.

28. Kann L, Kinchen S, Shanklin SL, Flint KH, Hawkins J, Harris WA, et al. Youth Risk Behavior Surveillance - United States , 2013. Cent Dis Control Prev MMWR. 2014;63(4):1-168.

29. Miller AB, Esposito-smythers C, Leichtweis RN. Role of Social Support in Adolescent Suicidal Ideation and Suicide Attempts. J Adolesc Heal. 2015;56(3):286-92.

30. Kaur G, Puar SS. Relationship Between Mental Health And Academic Stress Of Senior Secondary School Students. Int J Educ. 2017;7:39-45.

31. Lubis NL. Depresi Tinjauan Psikologi. Jakarta: Kencana; 2009.

32. Jayanthi P, Thirunavukarasu M, Rajkumar R. Academic Stress and Depression among Adolescents: A Cross-sectional Study. Indian Pediatr. 2015;52:217-9.

33. Ribeiro JD, Huang X, Fox KR, Franklin JC. Depression and hopelessness as risk factors for suicide ideation, attempts and death: meta-analysis of longitudinal studies. $\mathrm{Br} \mathrm{J}$ Psychiatry. 2018;212:279-86.

34. Handayani, Tita Septi. "Rational Emotive Behavior Therapy (Rebt) Dalam Efeknya Terhadap Frekuensi Inisiasi Konsumsi Rokok Pada Remaja Laki-Laki Di Kota Bengkulu." Jurnal Ilmiah Ilmu Keperawatan Indonesia 8.03 2018: 462-467.

35. Anyan F, Hjemdal O. Adolescent stress and symptoms of anxiety and depression: Resilience explains and differentiates the relationships. J Affect Disord. 2016. 